\title{
The Liver-Lung Vascular Connection
}

\author{
Michael J. Krowka, MD
}

Division of Pulmonary and Critical Care, Transplant Research Center, Mayo Clinic, Rochester MN, USA

\section{ABSTRACT}

Since the 1950's and 1960's it is well known that liver dysfunction can induce two distinct lung vascular disorders. We commonly refer to these disorders as hepatopulmonary syndrome (HPS) and portopulmonary hypertension (POPH). This concise review is intended to update the clinician on the current understanding and management of HPS and POPH that has evolved over the last 10 years. Each disorder is discussed in 5 parts: 1) diagnostic criteria/screening/clinical presentation; 2) pathophysiology;3) epidemiology/natural history; 4) medical management; and 5) implications for liver transplant (LT). A summary table is provided to compare these clinically significant pulmonary vascular disorders. (BRN Rev. 2017;3:204-19)

Corresponding author: Michael J. Krowka, krowka@mayo.edu

Key words: Hepatopulmonary syndrome. Liver transplant (LT). Portopulmonary hypertension $(\mathrm{POPH})$. 


\section{INTRODUCTION}

Liver dysfunction can result in two clinically significant lung vascular disorders - hepatopulmonary syndrome (HPS) and portopulmonary hypertension $(\mathrm{POPH})^{1}$. These pulmonary abnormalities can be extremely debilitating, distinct in pathophysiology, treatment approaches and outcomes ${ }^{2}$. The relevance of HPS or $\mathrm{POPH}$ is magnified in patients considered for liver transplant (LT) due to related/increased morbidity and mortality ${ }^{3}$. Although the vascular link between the liver and lung appears straightforward (all effluent from the hepatic veins drain into the pulmonary arterial/capillary bed), this pathway allows an unpredictable sequence of pulmonary vascular change presumably due to a myriad of circulating factors present in the setting of hepatic dysfunction. These factors, in combination with genetic predisposition, may cause pulmonary vascular dilatation and angiogenesis leading to arterial hypoxaemia (in HPS), or result in vascular obstruction due to endothelial/smooth muscle proliferation and platelet aggregation leading to pulmonary artery hypertension (in $\mathrm{POPH})^{3}$.

Complicating the liver-lung interaction is the lack of correlation between the severity of clinical liver dysfunction and existence and severity of these pulmonary vascular syndromes ${ }^{3}$.

\section{HPS}

\section{Diagnostic criteria/Screening/ Clinical presentation}

Specific diagnostic criteria for HPS proposed by the 2004 European Respiratory Society Task
TABle 1. Diagnostic criteria ${ }^{1,2}$

\begin{tabular}{|c|}
\hline Hepatopulmonary syndrome \\
\hline Liver disease (usually cirrhosis with portal hypertension) \\
\hline $\begin{array}{l}\text { Intrapulmonary vascular dilatations } \\
\text { - Positive contrast-enhanced transthoracic echocardiography*; or } \\
\text { - Brain uptake following lung perfusion scan with }{ }^{99} \mathrm{TC} \text { macroag- } \\
\text { gregated albumin }{ }^{\dagger}\end{array}$ \\
\hline $\begin{array}{l}\text { Abnormal arterial oxygenation } \\
-\mathrm{PaO}_{2}<80 \mathrm{mmHg} \text {; and/or } \\
-\mathrm{AaPO}_{2} \geq 15 \mathrm{mmHg}(>20 \mathrm{mmHg} \text { if age }>64)^{\ddagger}\end{array}$ \\
\hline Portopulmonary hypertension \\
\hline $\begin{array}{l}\text { Portal hypertension } \\
\text { - Right heart catheterization: } \\
\text { - Mean pulmonary artery pressure (mPAP) }>25 \mathrm{mmHg} \\
\text { - Pulmonary vascular resistance (PVR) }>3 \text { wood units } \\
\left(240 \text { dynes.s. } \mathrm{cm}^{-5}\right) \\
\text { - Pulmonary artery wedge pressure (PAWP) }<15 \mathrm{mmHg}\end{array}$ \\
\hline 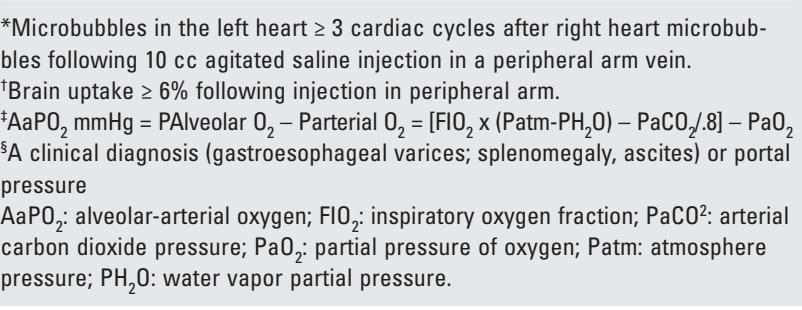 \\
\hline
\end{tabular}

Force on pulmonary-hepatic disorders and the 2016 International Liver Transplant Society Practice (ILTS) Guidelines are shown in table 1 .

HPS is characterized by arterial hypoxaemia due to intrapulmonary vascular dilatations (IPVD). Hypoxaemia is quantified by arterial blood gases that measure partial pressure of oxygen $\left(\mathrm{PaO}_{2}\right)$ and allow calculation of the alveolar-arterial oxygen $\left(\mathrm{AaPO}_{2}\right)$ gradient ${ }^{4}$. IPVD are documented by the presence positive contrast echocardiography (abnormal left heart opacification by microbubbles $\geq 3$ cardiac cycles after right heart microbubble presence following peripheral vein injection of agitated saline) or abnormal brain uptake following lung perfusion after peripheral vein injection of ${ }^{99 \mathrm{~m}} \mathrm{Tc}$ macro aggregated albumin) (Fig. 1). Transoesophageal 


\section{BRN Rev. 2017;3}

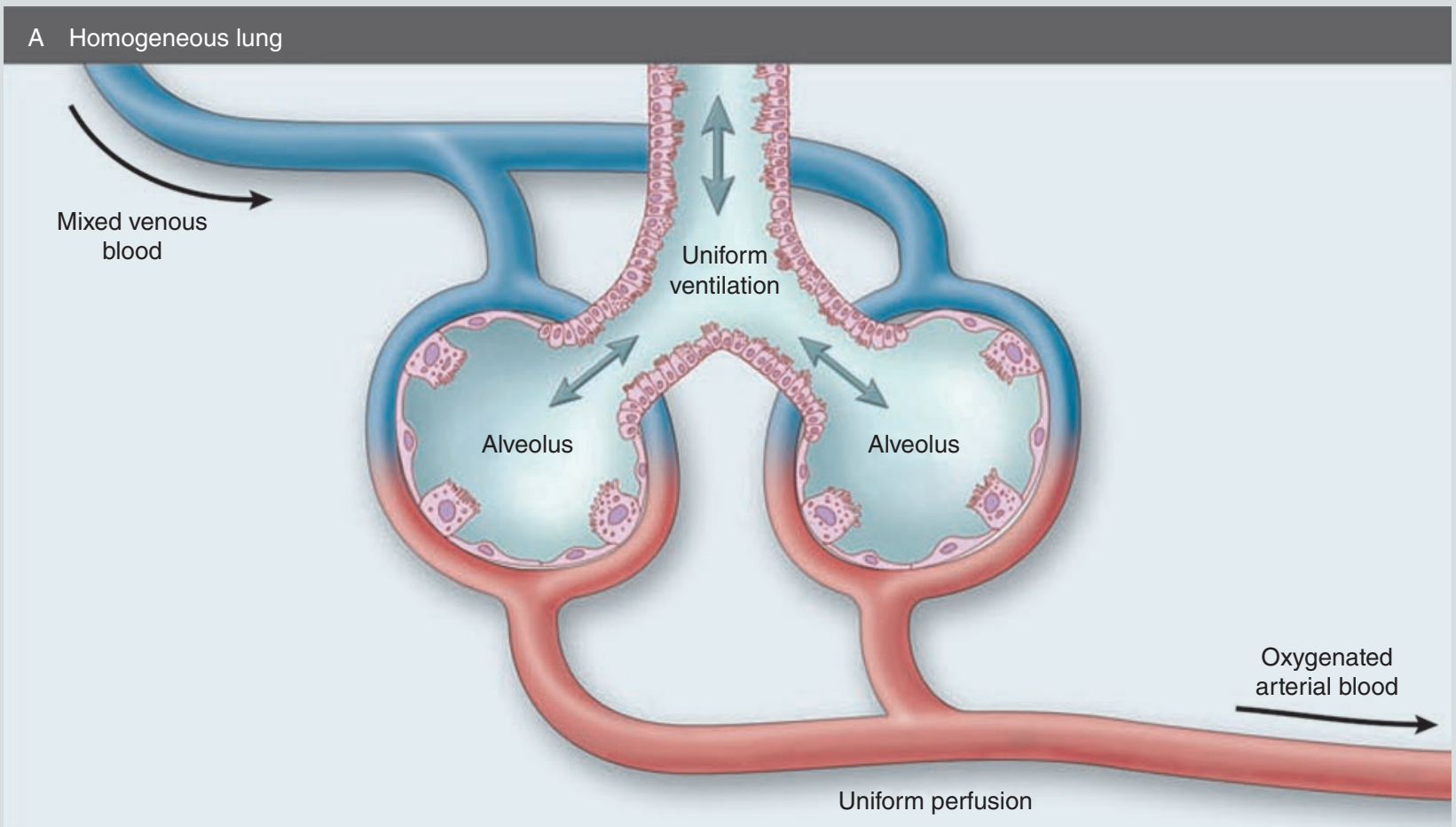

B Hepatopulmonary syndrome

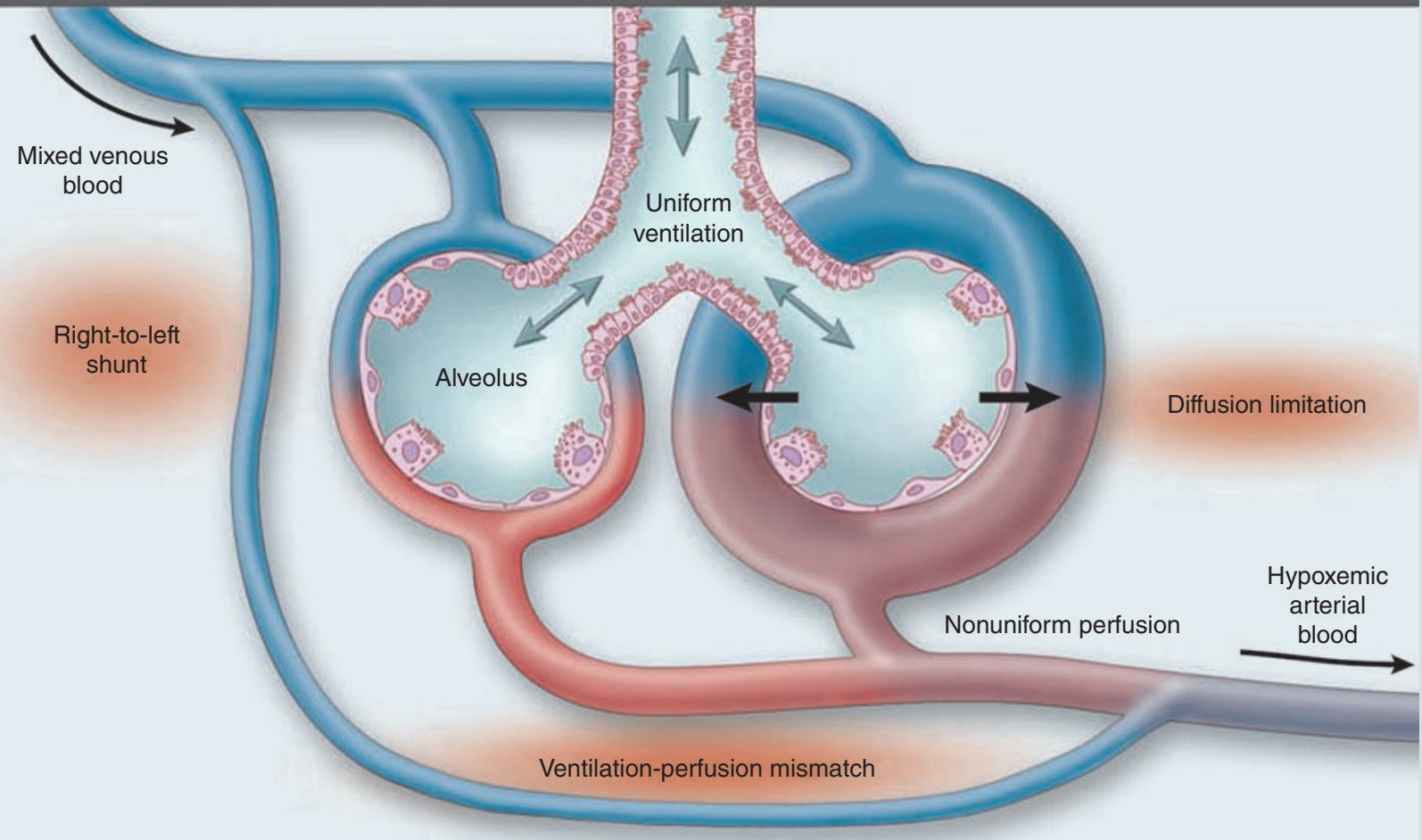

FiguRE 1. The mechanisms for arterial hypoxaemia in hepatopulmonary syndrome (HPS). A: normal alveolar-capillary ventilation-perfusion relationship. B: dilated capillary bed results in poor diffusion of $\mathrm{O}_{2}$ into the blood flow. Fast pulmonary transit time due to high cardiac output, as well as uncommon existence of anatomic shunts contribute to hypoxaemia. In summary, the main reason for hypoxaemia in HPS is a mismatch of ventilation to perfusion (reproduced with permission from Rodriguez-Roisin $R$ et al. ${ }^{2}$ ). 
echocardiography is the non-invasive test of choice to exclude a possible patent foremen ovale or atrial septal defect right to left shunt contributing to "early" left heart opacification of microbubbles ${ }^{2}$.

Screening and follow-up for HPS by finger pulse oximetry has been advocated. Oxygen saturations $\left(\mathrm{SO}_{2}\right)$ less than $96 \%$ have been associated with a high frequency of HPS 5 . However, many HPS patients have normal $\mathrm{SO}_{2}$, thus, the definitive diagnosis of HPS requires determination of $\mathrm{PaO}_{2}$ and/or $\mathrm{AaPO}_{2}$ gradient in adults and children ${ }^{6}$.

Clinically, the existence of spider angiomas of the skin, digital clubbing and cyanosis are frequent findings in HPS; exertional dyspnoea is the primary symptom, but dyspnoea can have many aetiologies in patients with advanced liver disease ${ }^{2}$. Pulmonary function testing usually demonstrates a nonspecific, reduced single breath diffusing capacity. Lung volumes and expiratory airflow are otherwise normal. Increased exhaled nitric oxide (NO) has been well documented in HPS, however, reducing exhaled NO levels, may not be associated with improvement in hypoxaemia?.

Chest imaging may suggest an interstitial pattern in the lung bases due to a predominance of dilated precapillary and capillary blood vessels. Rarely, discrete arteriovenous communications can be seen on computed tomography (CT) scans of the chest. Pulmonary angiography is indicated if severe hypoxaemia exists and the response to $100 \%$ inspired oxygen $\left(\mathrm{O}_{2}\right)$ is poor $\left(\mathrm{PaO}_{2}<300 \mathrm{mmHg}\right)^{8}$. Angiography would be conducted for the purpose of embolizing discrete arteriovenous communications.

\section{Pathophysiology}

The HPS pathophysiology of IPVD causing arterial hypoxaemia at the precapillary and capillary levels (macro and microscopic) is based upon autopsy data and a common bile duct ligation (CBDL) rat model ${ }^{9,10}$. The contributions of ventilation-perfusion mismatching, diffusion limitation and anatomic shunting noted in humans are variable and shown schematically (Fig. 2). Importantly, the usual response to $100 \%$ inspired $\mathrm{O}_{2}$ in HPS patients may be excellent (> $500 \mathrm{mmHg}$ ) reflecting the dominant ventilation perfusion mismatching in this syndrome.

From a mediator perspective, the factors that induce the predominant features of IPVD (vasodilatation and angiogenesis) are complex. Currently, the three mediators of greatest interest are endothelin (ET) -1, NO and vascular endothelial growth factor (VEGF) ${ }^{10}$.

In the CBDL model and humans, bile duct epithelium (cholangiocytes) is the source of increased circulating levels of ET-1. When ET-1 binds to upregulated ET-B receptors in the pulmonary vascular bed (up regulation noted in the setting or portal hypertension), pulmonary nitric oxide synthase (eNOS) is activated leading to $\mathrm{NO}$-induced vasodilatation ${ }^{11}$.

The activation of inducible nitric oxide synthase (iNOS), another route to cause NO-induced vasodilatation, results from endotoxemia, leading to the recruitment and activation of intrapulmonary vascular macrophages. The macrophages produce the cytokine tumour necrosis factor-alpha which in turn triggers iNOS activation. Another consequence of these macrophages, which may be increased by ET-1 

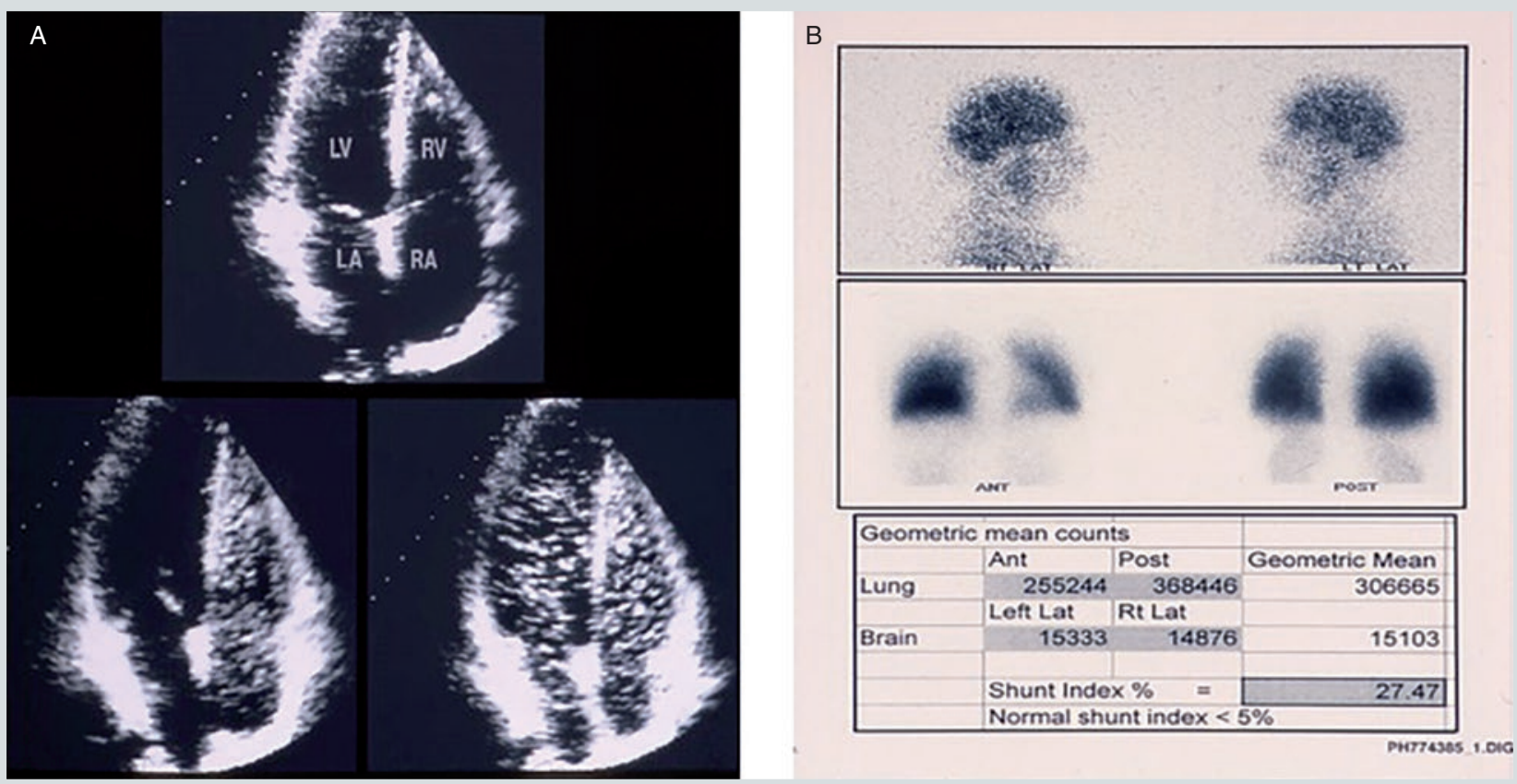

FigurE 2. Imaging methods to demonstrate intrapulmonary vascular dilatation (IPVD) in a hepatopulmonary syndrome (HPS) patient with: partial pressure of oxygen $\left(\mathrm{PaO}_{2}\right)=44 \mathrm{mmHg}$. A: "positive" contrast transthoracic echocardiogram - normal four-chamber view (top); microbubble opacification of right heart (left panel); delayed microbubble opacification of left heart (right panel). B: abnormal uptake in the brain $(>6 \%)$ after peripheral arm injection of technetium ${ }^{99 m}$-labeled TC macroaggregated albumin.

LA: left atrium; LAT: latency; LV: left ventricle; RA: right atrium; RT LAT: rigth latency; RV: right ventricle.

levels, is to activate VEGF signalling pathways, thus inducing angiogenesis. Anti-angiogenesis therapy with sorafenib, a kinase inhibitor, can inhibit VEGF signalling, angiogenesis and improve gas exchange in the CBDL rat model ${ }^{11}$.

\section{Epidemiology/Natural history}

HPS is not uncommon. Depending on the $\mathrm{AaPO}_{2}$ and $\mathrm{PaO}_{2}$ criteria used and the clinical setting, HPS frequency ranges from $4-32 \%{ }^{2}$. The frequency of IPVD without arterial hypoxaemia is common, occurring in approximately $50 \%$ in liver transplant candidates ${ }^{12}$. It is important to recognize that approximately $30 \%$ of HPS patients may have additional pulmonary reasons (pulmonary fibrosis, chronic obstructive lung disease, hepatic hydrothorax) for arterial hypoxaemia ${ }^{13}$. The use of macro-aggregated albumin lung perfusion scan ( ${ }^{9} \mathrm{~m}$ Tc-MAA) with brain uptake can help to distinguish between HPS versus non-HPS causes of arterial hypoxaemia. Brain uptake is specifically seen in HPS and not in other hypoxaemia causes ${ }^{2}$.

There is no relationship to any given hepatic disorder, but HPS most commonly occurs in chronic liver disease and portal hypertension. Quality of life is worse in HPS versus non-HPS patients ${ }^{14}$. Rarely, HPS has been documented in acute liver disease and extra-hepatic venacava obstruction. Genetic polymorphisms have been identified in HPS $^{15}$. 
Finally, 5-year survival in $64 \mathrm{HPS}$ patients was approximately $20 \%$ for those who did not undergo liver transplant, survival being worse in Child-Pugh class severity liver disease ${ }^{16,17}$.

\section{Medical management}

In HPS oxygenation can worsen over time, but the change is gradual with $\mathrm{PaO}_{2}$ decreasing an average of $5 \mathrm{mmHg}$ per year; therefore, annual monitoring is advised. Despite anecdotal reports of medications to improve oxygenation in HPS, there is no proven medical therapy, aside from supplemental $\mathrm{O}_{2}$ to improve hypoxaemia ${ }^{3}$. Supplemental $\mathrm{O}_{2}$ via nasal cannula (up to 5 litres/minute to maintain $\mathrm{SO}_{2}>90 \%$ ) at rest, with exercise, and during sleep improves arterial oxygenation (and symptoms of dyspnoea) in the vast majority of cases ${ }^{3}$. There is no proven role for transjugular intrahepatic portosystem shunting (TIPS) in treating $\mathrm{HPS}^{18,19}$.

A current prospective, randomized National Institutes of Health (NIH) study is underway in the US using sorefanib, a kinase inhibitor to block angiogenesis ( $<$ ClinicalTrials.gov $>$ ). This study is based upon findings of sorafenib improving oxygenation and blocking angiogenesis in the HPS CBDL animal model.

\section{Implications for liver transplant}

In the early days of LT, the existence of severe $\mathrm{HPS}\left(\mathrm{PaO}_{2}<50 \mathrm{mmHg}\right)$ and ${ }^{99 \mathrm{~m}} \mathrm{TcMAA}>20 \%$ were considered an absolute contraindication to LT and high risk for LT, respectively ${ }^{2,20}$. This is no longer the case due to successful patient selection and management strategies ${ }^{3}$. Clinically significant $\mathrm{HPS}\left(\mathrm{PaO}_{2}<70 \mathrm{mmHg}\right)$ is now considered an indication for $\mathrm{LT}^{3}$.

Because of poor outcomes in the setting of HPS without LT and lack of correlation to the severity of liver disease, a higher priority is given to HPS patients needing LT. The model for end-stage liver disease (MELD) score provides such a basis for LT priority in the United States $^{21}$. Since the MELD score correlates poorly with the severity of HPS, "MELD exception" can be granted when $\mathrm{PaO}_{2}$ is less than $60 \mathrm{mmHg}$ due to HPS. The MELD score increases every 3 months as long as $\mathrm{PaO}_{2}$ remains less than $60 \mathrm{mmHg}$.

In a study of 973 HPS patients given MELD exception (2002-2012), overall mortality was significantly lower (presumably due to earlier LT) compared to non-HPS patients awaiting LT. Overall 1, 3 and 5-year post-LT survival after HPS MELD exception was not significantly different from non-HPS post-LT survival ${ }^{22}$.

Despite being an indication for LT, there remains a higher risk of post-LT mortality in HPS, more so when very severe hypoxaemia $\left(\mathrm{PaO}_{2}<44 \mathrm{mmHg}\right)$ exists ${ }^{22}$. Recently, centres with extensive experience in managing/transplanting HPS patients, have demonstrated excellent outcomes and syndrome resolutions when $\mathrm{PaO}_{2}$ is less than $50 \mathrm{mmHg}$ with no lower limit of $\mathrm{PaO}_{2}$ that would preclude $\mathrm{LT}^{23,24}$.

Guidelines for the pre- and post-LT management of HPS have been published ${ }^{3}$. Continual use of supplemental $\mathrm{O}_{2}$ with a goal of $\mathrm{SO}_{2}$ $>90 \%$ is strongly recommended. The intraoperative management of HPS patients is not affected by the type of anaesthesia ${ }^{3}$. Early 
extubation is recommended and well tolerated. In the immediate post-LT period (24-72 hours) it is not unusual for oxygenation to worsen due to blood product/fluid administration and atelectasis. Rarely, the use of inhaled NO or prostacyclin has been used to alter the ventilation-perfusion mismatching post LT to improve oxygenation. The use of extracorporeal membrane oxygenation (ECMO) post-LT has been reported in the rare refractory hypoxaemia situations post-LT ${ }^{3}$.

Although complete resolution of HPS following successful LT occurs in most cases, the time to resolution varies and is correlated directly to the severity of pre-LT hypoxaemia; HPS resolution usually takes weeks to months to occur $^{25-28}$. Rarely, pulmonary artery hypertension may evolve post-LT following successful resolution of $\mathrm{HPS}^{29}$.

Living donor LT for HPS can have excellent outcomes $^{30,31}$. Comorbidities that complicate HPS such as common variable immunodeficiency (CVID), metastatic malignancy, or severe cardiopulmonary abnormalities may preclude LT candidacy ${ }^{3}$.

\section{POPH}

\section{Diagnostic criteria/Screening/ Clinical presentation}

All-cause pulmonary hypertension (PH) is defined haemodynamically by right heart catheterization (RHC) as a mean pulmonary artery pressure $(\mathrm{mPAP})>25 \mathrm{mmHg}^{32}$. Distinguishing between pulmonary artery hypertension $(\mathrm{PAH})$, precapillary $\mathrm{PH}$ and post-capillary pulmonary is very important in terms of therapy options and outcomes. The key point to assess $\mathrm{PH}$ in liver disease (and establish the POPH diagnosis) is an accurate and complete pulmonary haemodynamic assessment obtained by $\mathrm{RHC}^{3}$. Other causes of $\mathrm{PH}$ must be excluded when making the clinical diagnosis of POPH. Specific diagnostic criteria for $\mathrm{POPH}$ proposed by the 2004 European Respiratory Society task force on pulmonary-hepatic disorders and the 2016 ILTS Practice Guidelines are shown in table 1. Examples of varying reasons for $\mathrm{PH}$ suggested by screening echocardiography, confirmed by RHC, that have occurred in the setting of liver disease are shown in table 2.

Screening for POPH is best accomplished noninvasively by a standard transthoracic echocardiogram (TTE) ${ }^{33}$. The velocity of blood flowing back through the tricuspid valve during systole-tricuspid regurgitant (TR) velocity - reflects the pressure gradient between the right atrium (RA) and right ventricle (RV). RV systolic pressure (RVSP) is an estimate of the pulmonary artery systolic pressure assuming a normal pulmonic valve. This relationship between flows and RVSP is given by the modified Bernoulli formula:

$\operatorname{RVSP}(\mathrm{mmHg})-\mathrm{RA}(\mathrm{mmHg})=4 \times \mathrm{TR}(\mathrm{m} / \mathrm{sec})^{2}$

RA pressure can be estimated TTE determination of inferior vena cava collapse during inspiration (none; mild; moderate).

The practice at the Mayo Clinic is to proceed to RHC when RVSP $\geq 50 \mathrm{mmHg}$ or the RV is enlarged with reduction in function. The latter is noninvasively characterized by tricuspid annular plane systolic excursion and longitudinal strain measurements (G. Kane, MD, 
TABLE 2. Scenarios with increased mean pulmonary artery pressures

\begin{tabular}{|l|c|c|c|c|c|c|c|}
\hline & $\begin{array}{c}\text { TTE RVSP } \\
(\mathbf{m m H g})\end{array}$ & $\begin{array}{c}\mathrm{mPAP} \\
(\mathbf{m} \mathrm{mHg})\end{array}$ & $\begin{array}{c}\text { PASP } \\
(\mathbf{m m H g})\end{array}$ & $\begin{array}{c}\text { PAWP } \\
(\mathbf{m m H g})\end{array}$ & $\begin{array}{c}\text { CO } \\
(\mathbf{L} / \mathbf{m i n})\end{array}$ & $\begin{array}{c}\text { PVR } \\
\left.\text { (dynes.s.cm }{ }^{-5}\right)\end{array}$ & Interpretation \\
\hline Case \#1 & 69 & 33 & 48 & 7 & 11.9 & $2.2(175)$ & High flow state \\
\hline Case \#2 & 50 & 34 & 49 & 23 & 14.9 & 0.6 (59) & $\begin{array}{c}\text { Diastolic dysfunction } \\
\text { (Pulmonary venous PH) }\end{array}$ \\
\hline Case \#3 & 68 & 52 & 72 & 11 & 4.0 & 10.2 (846) & POPH (Pulmonary artery PH) \\
\hline
\end{tabular}

Case \#1: represented a high flow state and required no pulmonary hypertension pulmonary artery targeted therapy. Case \#2: had volume overload and diastolic dysfunction with normal renal function. Case \#3: had severe portopulmonary hypertension (POPH) with severe right ventricle (RV) enlargement and dysfunction.

CO: cardiac output; mPAP: mean pulmonary artery pressure; PASP: pulmonary artery systolic pressure; PAWP: pulmonary artery wedge pressure; PH: pulmonary hypertension; POPH: portopulmonary hypertension; PVR: pulmonary vascular resistance; RVSP: right ventricular systolic pressure; TTE: transthoracic echocardiogram.

Mayo echocardiography laboratory; personal communication).

\section{Pathophysiology}

Unlike HPS, there is no animal model for POPH. The possible reasons for the development of clinical POPH are complex. Importantly, the resulting pulmonary artery hypertension does not correlate with the severity or aetiology of liver dysfunction ${ }^{3}$.

An obstruction to pulmonary arterial flow is the key feature of POPH. Such obstruction, quantifies at $\mathrm{RHC}$, results in both increased mean mPAP and pulmonary vascular resistance (PVR). Although the literature describing the human pathology found in POPH is scant, the morphology of such a pulmonary vascular disorder has been described as either thromboembolic or plexogenic and, not uncommonly, co-existence of both ${ }^{34}$.

The thromboemboli described have been usually microscopic. The origin of such emboli has been attributed to the portal venous system and its collateral channels. Organizing clot in varicose oesophageal and gastric veins has been documented and portal vein thrombi reaching the lung via direct portacaval shunts have been reported ${ }^{34}$.

Plexogenic arteriopathy refers to a disorganized proliferation of smooth muscle and endothelial cells of the small pulmonary arteries ${ }^{34}$. Ranging from isolated medial hypertrophy to eccentric and concentric fibrosis, associated with a vasoactive component, these lesions may also be accompanied by vasodilatory pathways that may "off load" the constrictive component. The role of platelet aggregates further contributing to vascular occlusion has been proposed, releasing mediators such as serotonin (causing vasoconstriction) and platelet derived growth factor (stimulating growth of smooth muscles); platelet aggregates have been demonstrated at autopsy in association with severe $\mathrm{POPH}^{34}$.

At the cellular level, three lines of evidence are important in understanding the pathophysiology (and subsequent treatment) of POPH; 1) a deficiency of endothelial prostacyclin synthase; 2) the effect of increased circulating ET-1 levels; and 3) mechanisms to block pulmonary artery vasoconstriction ${ }^{35,36}$. 
An important observation was the lack of prostaglandin synthase expression (by immunohistochemistry) in the pulmonary arteries and plexiform lesions in cirrhosis patients ( 3 autopsies; one explant) $)^{37}$. Thus, a potent vasodilator (prostacyclin) is absent (or levels reduced) and forms the basis for synthetic prostacyclin replacement as a therapeutic option.

ET-1 is one of the most potent vasoconstrictors implicated in the pathogenesis of idiopathic pulmonary artery hypertension (IPAH). Not only is there a strong pathologic similarity between IPAH and POPH, but in cirrhosis, ET-1 levels are elevated compared to controls. As a corollary, it has been shown that a strong association exists between increased ET-1 blood levels in the pulmonary artery and the presence of POPH. This finding is the basis for a therapeutic approach using ET receptor antagonists ${ }^{35}$.

Phosphodiesterase type 5 (PDE-5) enzymes normally functions to metabolize cyclic guanosine monophosphate (cGMP). cGMP induces vasodilation through relaxation of arterial smooth muscle cells. The inhibition of PDE-5 thus favours vasodilation. Specifically related to $\mathrm{POPH}$, since the pulmonary arterial bed has a high concentration of cGMP, it is theoretically useful to inhibit that enzyme. This approach has been successful in IPAH, and thus it is inferred, but not proven, that a similar pathophysiology may exist in $\mathrm{POPH}^{35}$.

Finally, in nearly all patients with portal hypertension, a high flow state driven by the mesenteric vasodilation, results in a persistent elevation of cardiac output. This high flow state may contribute to a shear stress effect to damage the pulmonary circulation, contributing to pulmonary artery hypertension over time ${ }^{36}$.
Overall in the setting of portal hypertension, circulating substances (aside from ET-1) may bypass the normal metabolism conducted by the liver, reaching the pulmonary circulation via portosystemic shunts (such as gastric/oesophageal varices or portacaval shunts) and affecting the pulmonary arterial bed. An imbalance of such factors (a lack of vasodilation; an excess of vasoconstrictors, such as thromboxane A-2, interleukins 1 and 6), along with a likely genetic predisposition to $\mathrm{POPH}$, contributes to a complex pathophysiology which may or not be predictably reversible at a given stage of evolution ${ }^{36}$.

\section{Epidemiology/Natural history}

The frequency of POPH depends upon the diagnostic criteria followed and the populations studied. Approximately 10\% of the population in the French Registry of PAH had $\mathrm{POPH}^{38}$. Variations in selecting cut-offs for normal PVR (120 versus 240 dynes $/ \mathrm{s} / \mathrm{cm}^{-5}$ ), have resulted in varying prevalence estimates.

In the largest POPH screening and RHC study conducted, it is notable that bias was introduced since only those with an echocardiographic RVSP greater than $50 \mathrm{mmHg}$ went on to have $\mathrm{RHC}^{33}$. In that study, out of the 1,235 who had echocardiograms, 101 (11\%) underwent RHC. Using the criteria shown in table 1 $(66 \%)$ had true POPH resulting in a POPH frequency of $5.6 \%$ in that time span of all liver transplant candidates. Patients with RVSP in the range $40-50 \mathrm{mmHg}$, mild $\mathrm{POPH}$, may have been missed. Overall, 5.3-8.5\% of liver transplant candidates are reported to have $\mathrm{POPH}^{3}$.

The 5-year survival in POPH (liver transplants excluded and uncontrolled for therapies) in a 


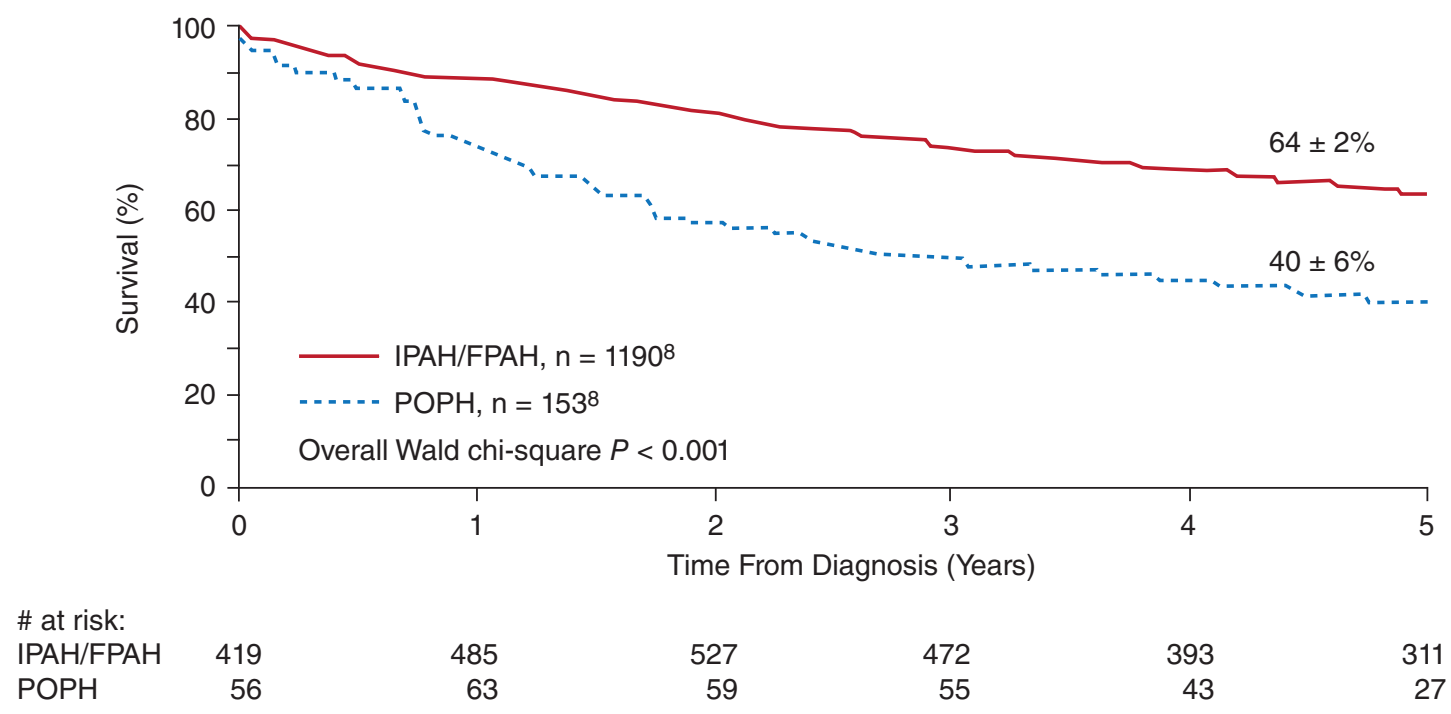

Figure 3. Portopulmonary hypertension (POPH) 5-year survival in the US-based REVEAL Registry. Patients with POPH were compared to patients with idiopathic/familial pulmonary artery hypertension (IPAH/FPAH). Patients with POPH who underwent liver transplant were excluded (reproduced with permission from Krowka MJ et al. ${ }^{39}$ ).

cohort of 155 POPH patients was $40 \%$ in the largest multicentre experience to date ${ }^{39}$. A 14\% 5 -year survival was reported in those with mPAP > $35 \mathrm{mmHg}$ not treated and not transplanted $^{40}$. In a retrospective study of $80 \mathrm{POPH}$ patients, unexpectedly, 20/34 (59\%) who underwent contrast TTE had IPVD. Including 5 patients with IPVD (all died post-LT) transplanted, they had worse overall 5-year survival (9 versus 70\%) compared to those without IPVD despite similar baseline arterial oxygenation, PVR and mPAP41 (Fig. 3).

\section{Medical management}

There have been no prospective controlled trials using current pulmonary artery target therapies to specifically treat $\mathrm{POPH}^{35}$. The results of $\mathrm{POPH}$ treatment in the small series and case reports have been favourable in many cases and are characterized by the following: reduction in $\mathrm{MPAP}$, reduction in PVR, increase in cardiac output, improvement in right ventricular function by echocardiography and, in highly selected patients, improvement in pulmonary hemodynamics that would allow successful LT ${ }^{35,36}$.

Since POPH is recognized as a subgroup of PAH (and indistinguishable from IPAH from a pathologic perspective), clinicians have cautiously used several medication approaches in the setting of $\mathrm{POPH}^{32,35}$.

\section{Prostacyclin analogues}

The lack of prostacyclin synthase in the endothelial cells of patients with IPAH, as well as 
cirrhosis, led to the successful use of infusing continuous synthetic prostacyclin (epoprostenol via a central line 24/7) to treat POPH. Early IV epoprostenol experience in $48 \mathrm{POPH}$ patients from 5 studies demonstrated a mean decrease in mPAP by $-25 \%$; decrease in PVR by $-52 \%$; and increase in cardiac output by $38 \% 35,42$. Other studies have confirmed the long-term benefit of epoprostenol in POPH, as well as the successful use of other infused and inhaled prostanoids (treprostinil and iloprost) ${ }^{43}$. Oral prostanoids and an oral specific prostacyclin receptor agonist are now available to treat $\mathrm{PAH}$, but there has been no reported use in POPH to date. The optimal prostacyclin dose is usually what is tolerated in terms of drug-induced side effects (headache, bone pain, and diarrhoea). In addition, infusion rates of epoprostenol greater than $20 \mathrm{ng} / \mathrm{kg} / \mathrm{min}$ have been associated with very cardiac outputs and progressive splenomegaly, which in turn, can worsen thrombocytopaenia ${ }^{44,45}$.

\section{ENDOTHELIN RECEPTOR ANTAGONISM}

Documentation of a serum increase in the potent vasoconstrictor ET-1 in cirrhotic patients led to uncontrolled treatments of endothelin receptor (ER) blockade in $\mathrm{POPH}^{46}$. Specifically, the pulmonary arterial bed has endothelium- ET-A and smooth muscle - ET-B receptors that produce vasoconstriction and vasodilation, respectively. Both oral bosentan (a non-specific ER antagonist) and oral ambrisentan (a more specific for the ET-A receptor) have demonstrated improvement in $\mathrm{POPH}$ pulmonary haemodynamics (reductions in MPAP and PVR) over a 12-48-week period $^{46-48}$. Liver toxicity has limited the use of bosentan; significant peripheral oedema has accompanied the use ambrisentan ${ }^{47,48}$. A third ER antagonist, macitentan, is a significant addition for the treatment of POPH in that it is the first agent to be used in a multicentre trial ("PORTICO") in only patients with POPH. This prospective, double-blind, placebo-controlled, international trial randomizes 48 patients to each arm; entry criteria includes mPAP $>25 \mathrm{mmHg}$ and PVR $>320$ dynes.s.cm ${ }^{-5}$. Primary outcome is a percentage reduction in mean (geometric) PVR at 12 weeks. Results are expected in 2018 $(<$ ClinicalTrials.gov $>$ ).

\section{PDE-5 INHIBITION}

Treating POPH with a medication that causes pulmonary vasodilation via PDE-5 inhibition by locally increasing $\mathrm{NO}$ (preventing the breakdown cGMP) appears effective $e^{49,50}$. Pulmonary haemodynamic improvement in POPH using the short-acting oral sildenafil (numerous reports) and long-acting oral tadalafil PDE-5 drugs have been published, with the latter described as reducing both portal (hepatovenous pressure gradient) and pulmonary artery pressures ${ }^{36}$. It remains unclear if sildenafil can favourably alter portal pressures. Both drugs appear to be well tolerated in POPH and do not adversely affect hepatic function. In the large Canadian sildenafil series $(n=20$ POPH), treatment was successful (PVR decreased by a mean of -236 dynes.s.cm ${ }^{-5}$ at 6 months) and the drug was used in 2 patients with increased pulmonary artery wedge pressure (PAWP), but their outcome data was not reported $^{51}$. 


\section{GUANYLATE-CYCLASE STIMULATION}

The only prospective PAH treatment study that included POPH patients was PATENT-1, using the riociguat, a soluble guanylate cyclase (sGC) stimulator $^{35}$. In that study, $11 \mathrm{POPH}$ patients received riociguat. In this $\mathrm{POPH}$ subgroup the mPAP and PVR decreased, and 6-minute walk improved. The net effect of that drug is to induce vasodilation via sCG stimulation that is independent of any NO-sCG interactions that also cause vasodilation. Riociguat can also act synergistically with $\mathrm{NO}$ to cause vasodilation and antiproliferative effects, thus, the combined use of PDE-5 inhibitors and riociguat requires great caution in view of the possibilty to induce significant systemic hypotension.

\section{Caveats}

Beta blockers. A French study described the withdrawal of beta blockers in the setting of moderate to severe POPH has resulted in improvement of exercise capacity, cardiac output $(28 \%)$ and a decrease in PVR (19\%) with no change in mPAP ${ }^{52}$. This study demonstrated the removal of a negative chronotropic effect and possible vasoconstrictive effect of beta blockers. Thus, caution is advised when considering the addition of a beta blocker in $\mathrm{POPH}$ patients, due to the possible adverse effect on RV function.

Transjugular intrahepatic portosytemic shunt (TIPS). An immediate increase in right heart filling pressures due to increased preload may occur following the placement of TIPS. The expected increases in cardiac output and pulmonary artery pressures are mild and short lived (30 days) $)^{53}$. There is no proven role in the treatment of $\mathrm{POPH}$ (by presumably relieving the degree of portal hypertension). An elective TIPS procedure in the setting of RV dysfunction could theoretically have an immediate, deleterious cardiac effect.

\section{Implications for LT}

Importantly, screening for POPH by TTE is current policy followed by all LT centres in the United States ${ }^{3}$. Confirmation of suspected POPH requires RHC. Unlike LT in the setting of HPS, the existence of moderate to severe POPH poses several unique challenges in the LT candidate. The two most important observations over the years have been 1) intraoperative death during LT can occur due to acute right failure - with or without pre-LT pulmonary artery targeted therapies (PATT) $)^{5,55}$; and 2) successful LT, despite a successful (intravenous and/oral PATT) and a successful transplant procedure, partial or complete resolution $\mathrm{POPH}$ is unpredictable ${ }^{56-63}$.

It has been thought to prevent progression of $\mathrm{POPH}$ and right heart failure, aggressive PATT combined with "early" LT would be prudent. To that end, and since the degree of POPH correlated poorly with severity of liver disease (and MELD score), MELD exception for POPH was introduced in 2006 in the United States LT programs ${ }^{64}$. If specific pulmonary hemodynamic criteria can be met (reducing mPAP to less than $35 \mathrm{mmHg}$ with therapy), additional MELD points are granted by the regional review boards in lieu of native MELD scores. A higher priority for LT is provided and granting MELD exception 
TABLE 3. Outcomes following liver transplant in portopulmonary hypertension (POPH)

\begin{tabular}{|l|c|c|c|}
\hline Year - Author & \# POPH transplanted & ATT stopped post-LT & Survival reported \\
\hline 2017 DeMartino $^{67}$ & 6 & Not reported & 1 -year $100 \%$ \\
\hline 2017 DuBrock $^{66}$ & 103 & Not reported & 1 -year $87 \%$ \\
\hline 2016 Verma $^{60}$ & 28 & Not reported & 5 -year $58 \%{ }^{*}$ \\
\hline 2016 Legros $^{59}$ & 5 & $60 \%$ by month 25 & 5 -year $53 \%$ \\
\hline 2014 Goldberg $^{65}$ & 73 & Not reported & 3 -year $64 \%$ \\
\hline 2014 Khaderi62 $^{62}$ & $76 \%$ by month 8 & $86 \%$ at 7.8 years \\
\hline 2012 Hollatz $^{63}$ & 7 & $64 \%$ by month 7 & 1 -year $100 \%$ \\
\hline 2008 Swanson $^{40}$ & 11 & $50 \%$ at one year & 1 -year $58 \%$ \\
\hline 2007 Ashfaq $^{57}$ & 12 & $82 \%$ by month 9 & 5 -year $67 \%$ \\
\hline 2004 Krowka $^{54}$ & 11 & Not reported & 30 -day $67 \%{ }^{\dagger}$ \\
\hline
\end{tabular}

Studies selected/summarized if POPH $n \geq 5$.

DuBrock, Verma, and Krowka studies only required mPAP $>25 \mathrm{mmHg}$ for the POPH diagnosis. All other studies required mPAP $>35 \mathrm{mmHg}$.

*POPH defined by mPAP $>25 \mathrm{mmHg}$ and increased PVR.

tPOPH defined by mPAP $>35 \mathrm{mmHg}$ and increased PVR

ATT: antitubercular treatment; LT: liver transplant; mPAP: pulmonary artery pressure; PATT: pulmonary artery targeted therapy; POPH: portopulmonary hypertension;

PVR: pulmonary vascular resistance.

for POPH is re-evaluated every 3 months by RHC. Unfortunately, such specific therapeutic criteria (as well as diagnostic criteria) have not been rigorously followed, thus complicating LT outcome analysis in the setting of POPH. In the largest US post LT survival analysis to date $(\mathrm{n}=155$ patients granted POPH MELD exception from 2006 to 2012), only $73(47 \%)$ actually fulfilled all MELD exception criteria ${ }^{65}$. A similar difficulty was noted in a separate US pre-LT waitlist analysis ( $\mathrm{n}=190$ patients granted POPH MELD exception from 2006 to 2014), where only 103 (54\%) fulfilled correct POPH diagnostic criteria ${ }^{66}$.

Despite these shortcomings several small series have reported successful LT (deceased donor and living donor) in the setting of treated moderate to severe $\mathrm{POPH}^{67}$. Normalization of pulmonary hemodynamics and discontinuation off all PATT post-LT has been reported in $50-82 \%$ of POPH patients post-LT (Table 3). Recent data suggest that POPH patients with mPAP $>35 \mathrm{mmHg}$ at the time of LT can have successful outcomes up to 1-year post $\mathrm{LT}^{68}$. Arguably, pre-LT normalization of PVR and RV function may be the best indicators for optimal post-LT outcomes and POPH resolution ${ }^{66}$.

Finally, it should be stressed that POPH, regardless of treatments, poses a higher risk for LT and the mere existence of POPH (unlike HPS), is not an indication for LT at this time ${ }^{3,69}$.

\section{CONCLUSION}

Comparisons between the two pulmonary vascular syndromes are summarized in table 4 . 
TABLE 4. Hepatopulmonary syndrome (HPS) and portopulmonary hypertension (POPH) comparisons

\begin{tabular}{|c|c|c|}
\hline Clinical issue & HPS & POPH \\
\hline Pathophysiology & Vasodilatation/angiogenesis & Obstruction to flow \\
\hline Presentation & Adults/children & Adults/children (uncommon) \\
\hline Related to age/gender & No & No \\
\hline Related to specific liver diseases & No & No \\
\hline Related to severity of liver diseases & No & No \\
\hline Genetic polymorphisms & Yes, documented & Yes, documented \\
\hline Intrapulmonary vascular dilatations & Diagnostic & Not uncommon \\
\hline Arterial deoxygenation & Mild $\rightarrow$ severe & Normal $\rightarrow$ mild \\
\hline Chest radiograph & Normal & Hilar enlargement/cardiomegaly \\
\hline TTE echocardiography & Diagnostic & Screening/not diagnostic \\
\hline 99mTcMAA lung/brain scanning & Estimates degree of IPVD & No diagnostic role \\
\hline Right heart catheterization & No role & Diagnostic \\
\hline Pulmonary angiography & If $\mathrm{PaO} 2<300 \mathrm{mmHg}$ * & No role \\
\hline Pulmonary vasodilator therapy & No role & Advised if $\mathrm{mPAP} \geq 35 \mathrm{mmHg}$ \\
\hline $\begin{array}{l}\text { Liver transplant } \\
\text { Indication } \\
\text { MELD Exception } \\
\text { Risk } \\
\text { Intraoperative death } \\
\text { Outcome }\end{array}$ & $\begin{array}{l}\text { Yes } \\
\text { Yes } \\
\text { Higher than normal } \\
\text { Never reported } \\
\text { Resolution expected }\end{array}$ & $\begin{array}{l}\text { No } \\
\text { Yes } \\
\text { Highest if } \mathrm{mPAP} \geq 50 \mathrm{mmHg}^{\dagger} \\
\text { Due to right heart failure } \\
\text { Resolution variable }\end{array}$ \\
\hline
\end{tabular}

The understanding and management of these syndromes have evolved for quite different reasons. An animal model for HPS has led to the first randomized trial (sorafenib) in HPS. Experienced centres have successfully transplanted the most severe cases of HPS. Despite the lack on an animal model, the advent of effective pulmonary artery targeted therapies has improved the outcomes in $\mathrm{POPH}$ and facilitated successful LT in highly selected patients. The results of the first randomized, controlled trial in POPH will be welcome. Unravelling the pathophysiology of these entities remains a high priority for those awaiting LT and those not appropriate for such surgery, yet debilitated by these syndromes. It is hoped that both of these liver-lung vascular problems will further benefit from innovative research and clinical approaches.

\section{ACKNOWLEDGEMENTS}

Sincere appreciation to my colleague, Roberto Rodriguez-Roisin, for our 25 years of collaborations and contributions on the topic of hepatopulmonary syndrome 


\section{CONFLICT OF INTEREST}

\author{
Dr. Michael J. Krowka has no conflicts of in- \\ terest to report. No funding.
}

\section{REFERENCES}

1. Rodriguez-Roisin R, Krowka MJ, Herve P et al. Pulmonary-Hepatic vascular disorders. Eur Respir J. 2004;24:861-80.

2. Rodriguez-Roisin R, Krowka MJ. Hepatopulmonary Syndrome: A liver-induced lung vascular disorder. N Engl J Med. 2008;358:2378-87.

3. Krowka MJ, Fallon MB, Kawut SK et al. International liver transplant society practice guidelines: diagnosis and management of hepatopulmonary syndrome and portopulmonary hypertension. Transplantation. 2016;100:1440-52.

4. Schenck P, Fuhrmann V, Madl C et al. Hepatopulmonary syndrome: prevalence and predictive value cut-offs for arterial oxygenation and their clinical consequences. Gut. 2002;51:853-9.

5. Hoerning A, Raub S, Neudorf $U$ et al. Pulse oximetry is insufficient for timely diagnosis of hepatopulmonary syndrome in children with liver cirrhosis. J Pediatrics. 2014;164:546-52.

6. Kochar R, Tanikella R, Fallon M. Serial pulse oximetry in hepatopulmonary syndrome. Dig Dis Sci. 2011;56:1862-8.

7. Gomez F, Barbera JA, Roca J et al. Effects of nebulized NG-nitro-L-arginine methyl ester in patients with hepatopulmonary syndrome. J Hepatol. 2006; 43:1084-91.

8. Krowka M, Wiseman G, Burnett $\mathrm{O}$ et al. Hepatopulmonary syndrome: A prospective study of relationships between severity of liver disease, $\mathrm{PaO}_{2}$ response to $100 \%$ oxygen, and brain uptake after ${ }^{99 \mathrm{~m} T c}$ MAA lung scanning. Chest. 2000;118:615-24.

9. Berthelot P, Walker JG, Sherlock $S$ et al. Arterial changes in the lungs in cirrhosis of the liver-lung spider nevi. N Engl J Med. 1966;274:291-8.

10. Zhang J, Luo B, Tang L et al. Pulmonary angiogenesis in a rat model of hepatopulmonary syndrome. Gastroenterology. 2009;136:1070-80.

11. Zhang J, Yang W, Hu B et al. Endothelin-1 activation of the endothelin B receptor modulates pulmonary endothelial CX3CL1 and contributes to pulmonary angiogenesis in experimental hepatopulmonary syndrome. Am J Pathol. 2014; 184:1706-14

12. Agarwal PD, Hughes PJ, Runo JR et al. The clinical significance of intrapulmonary vascular dilatations in liver transplant candidates. Clin Transpl. 2013;27:148-53.

13. Martinez G, Barbera J, Navasa M et al. Hepatopulmonary syndrome associated with cardiorespiratory disease. J Hepatol. 1999;30:882-9.

14. Fallon MB, Krowka MJ, Brown RS et al. Impact of hepatopulmonary syndrome on quality of life and survival in liver transplant candidates. Gastroenterology. 2008;135:1168-75.

15. Roberts KE, Kawut SM, Krowka MJ et al. Genetic risk factors for hepatopulmonary syndrome in patients with advanced liver disease. Gastroenterology. 2010;139:130-9.

16. Schenk P, Schoniger-Hekele M, Fuhrmann V et al. Prognostic significance of the hepatopulmonary syndrome in patients with cirrhosis. Gastroenterology. 2003;125:1042-52.

17. Swanson K, Wiesner R, Krowka M. Natural history of hepatopulmonary syndrome: impact of liver transplantation. Hepatology. 2005;41:1122-9.

18. Reigler JL, Lang KA, Johnson SP et al. Transjugular intrahepatic portosystemic shunt improves oxygenation in hepatopulmonary syndrome. Gastroenterology. 1995;109:978-83.

19. Corley DA, Scharschmidt B, Bass N et al. Lack of efficacy of TIPS for hepatopulmonary syndrome. Gastroenterology. 1997;113:728-31
20. Arguedas M, Abrams GA, Krowka MJ et al. Prospective evaluation of outcomes and predictors of mortality in patients with hepatopulmonary syndrome undergoing liver transplantation. Hepatology. 2003;37:192-7.

21. Fallon MB, Mulligan DC, Gish RC et al. Model of endstage liver disease (MELD) for hepatopulmonary syndrome. Liver Transpl. 2006;53:s105-7.

22. Goldberg DS, Krok K, Batra S et al. Impact of the hepatopulmonary syndrome MELD exception policy on outcomes of patients after liver transplantation: an analysis of the UNOS database. Gastroenterology. 2014;146:1256-5

23. Iyer V, Swanson KL, Cartin-Ceba R et al. Hepatopulmonary syndrome: favorable outcomes in the MELD exception era. Hepatology. 2013;57:2427-35.

24. Gupta S, Castel H, Rao RV et al. Improved survival after liver transplantation in patients with hepatopulmonary syndrome. Am J Transplant. 2010;10:354-63.

25. Deberaldini M, Arcanjo ABBB, Meio E. et al. Hepatopulmonary syndrome: morbidity and mortality after liver transplantation. Transplant Proc. 2008;40:3512-6

26. Taille C, Cadrenal J, Bellocq A et al. Liver transplantation for hepatopulmonary syndrome: a ten-year experience in Paris, France. Transplantation 2003;75:1482-9

27. Pascasio JM, Grilo I, Lopez-Pardo FJ et al. Prevalence and severity of hepatopulmonary syndrome and its influence on survival in cirrhotic patients evaluated for liver transplantation. Am J Transpl. 2014;14:191-9.

28. Schiffer E, Majno P, Giostra E et al. Hepatopulmonary syndrome increases the postoperative mortality rate following liver transplantation: a prospective study in 90 patients. Am J Transpl. 2006;6:1430-7.

29. Aucejo F, Miller C, Vogt D et al. Pulmonary hypertension after liver transplant with antecedent hepatopulmonary syndrome: a report of 2 cases and review of the literature. Liver Transpl. 2006;12:1278-82.

30. Carey EJ, Douglas DD, Balan V et al. Hepatopulmonary syndrome after living donor liver transplant and deceased donor liver transplantation: a single center experience. Liver Transpl. 2004;10:529-33.

31. Saigal S, Choudhar, Saraf N et al. Excellent outcome of living donor liver transplantation in patients with hepatopulmonary syndrome; a single center experience. Clin Transpl. 2013;27:530-4.

32. Simonneau G, Gatzoulis MA, Adatia I et al. Updated classification of pulmonary hypertension. JACC. 2013;62:D34-41.

33. Krowka MJ, Swanson KL, Frantz RP et al. Portopulmonary hypertension Results from a 10-year screening algorithm. Hepatology. 2006;44:1502-10.

34. Edwards BS, Weir EK, Edwards WD et al. Coexistent pulmonary and portal hypertension: Morphologic and clinical features. JACC. 1987;10:1233-8.

35. Dubrock H, Channick R, Krowka M. What's new in the treatment of portopulmonary hypertension? Expert Rev Gastroenterol Hepatol. 2015;9:983-92.

36. Cartin-Ceba R, Krowka M. Portopulmonary hypertension. Clin Liver Dis 2014;18:421-38

37. Tuder RM, Cool CD, Geraci MW et al. Prostacyclin synthase expression is decreased in lungs from patients with severe pulmonary hypertension. Am J Respir Crit Care Med. 1999;159:1925-32.

38. Le Pavec J, Souza R, Herve P et al. Portopulmonary hypertension: Survival and prognostic factors. Am J Respir Crit Care. 2008;178:637-43.

39. Krowka MJ, Miller DP, Barst RJ et al. Portopulmonary hypertension: A report from the US-based REVEAL registry. Chest. 2012;141:906-15.

40. Swanson KL, Wiesner RH, Nyberg SL et al. Survival in portopulmonary hypertension: Mayo clinic experience categorized by treatment subgroups. Am J Transplant. 2008;8:2445-53.

41. Fussner LA, Iyer V, Cartin-Ceba R. et al. Intrapulmonary vascular dilations are common in portopulmonary hypertension and may be associated with decreased survival. Liver Transpl. 2015;21:1355-64.

42. Krowka MJ, Frantz RP, McGoon MD et al. Improvement in pulmonary hemodynamics during intravenous epoprostenol (prostacyclin): A study of 15 patients with moderate to severe portopulmonary hypertension. Hepatology. 1999;30:641-8

43. Awdish RLA, Cajigas HR. Early initiation of prostcyclin portopulmonary hypertension: 10 years of a transplant center's experience. Lung. 2013;191:593-600.

44. Findlay JY, Plevak DJ, Krowka MJ, Sack EM, Porayko MK. Progressive splenomegaly after epoprostenol therapy in portopulmonary hypertension. Liver Transplant Surg. 1999;5:362-5. 
45. Fix OK, Bass NM, De Marco T et al. Long-term follow-up of portopulmonaryhypertension: effect of treatment with epoprostenol. Liver Transpl 2007; 13:875-85.

46. Hoeper MM, Seyfarth HJ, Hoeffken G et al. Experience with inhaled iloprost and bosentan in portopulmonary hypertension. Eur Resp J. 2007;30: 1096-102.

47. Savale L, Magnier R, Le Pavec J et al. Efficacy, safety, and pharmacokinetics of bosentan in portopulmonary hypertension. Eur Respir J. 2013;41:96-103.

48. Cartin-Ceba R, Swanson K, Iyer V et al. Safety and efficacy of ambrisentan for the treatment of portopulmonary hypertension. Chest. 2011;139:109-14.

49. Gough MS, White RJ. Sildenafil therapy is associated with improved hemodynamics in liver transplantation candidates with pulmonary arterial hypertension. Liver Transpl. 2009;15:30-6.

50. Hemnes AR, Robbins IM. Sildenafil monotherapy in portopulmonary hypertension can facilitate liver transplantation. Liver Transpl. 2009;15:15-9.

51. Fisher JH, Johnson SR, Chau C et al. Effectiveness of phosphodiesterase-5 inhibitor therapy for portopulmonary hypertension. Can Respir J. 2015; 22:42-6.

52. Provencher S, Herve P, Jais X et al. Deleterious effects of beta-blockers on exercise capacity and hemodynamics in patients with portopulmonary hypertension. Gastroenterology. 2006;130:120-6.

53. Stanley AJ, Redhead DN, Bouchier IA, Hayes PC. Acute effects of transjugular intrahepatic portosystemic stent-shunt (TIPS) procedure on renal blood flow and cardiopulmonary hemodynamics in cirrhosis. Am J Gastroenterology. 1998;93:2463-8.

54. Krowka MJ, Mandell, MS, Ramsay MAE et al. Heaptopulmonary syndrome and portopulmonaryt hypertension: a report of the multicenter liver transplant database. Liver Transpl. 2004;10:174-82.

55. Ramsay MAE, Simpson BR, Nguyen AT et al. Severe pulmonary hypertension in liver transplant candidates. Liver Transpl Surg. 1997;3:494-500.

56. Yoshida EM, Erb SR, Pflugfelder PW et al. Single-lung versus liver transplantation for the treatment of portopulmonary hypertension- a comparison of two patients. Transplantation. 1993;55:688-90.

57. Ashfaq M, Chinnakotla S, Rogers L et al. The impact of treatment of portopulmonary hypertension on survival following liver transplantation. Am J Transplant. 2007;7:1258-64.
58. Sussman N, Kaza V, Barshes N et al. Successful liver transplantation following medical management of portopulmonary hypertension: A single-center series. Am J Transplant. 2006;6:2177-82.

59. Legros L, Chabanne, C, Camus C et al. Oral pulmonary vasoactive drugs achieve hemodynamic eligibility for liver transplantation in portopulmonary hypertension. Dig Liver Dis. 2017;49:301-7.

60. Verma S, Hand F, Armstrong MJ et al. Portpulmonary hypertension: still an appropriate consideration for liver transplantation? Liver Transpl. 2016; 22:1637-42.

61. Raevens S, DePauw M, Reyntjens K et al. Oral vasodilator therapy in patients with moderate to severe portopulmonary hypertension as a bridge to liver transplantation. Eur J Gastroenterol and Hepatol. 2013;25:495-502.

62. Khaderi S, Khan R, Safdar Z et al. Long-term follow-up of portopulmonary hypertension patients after liver transplantation. Liver Transpl. 2014; 20:724-7.

63. Hollatz TJ, Musat A, Westphal S et al. Treatment with sildenafil and treprostinil allows successful liver transplantation in moderate to severe portopulmonary hypertension. Liver Transpl. 2012;18:686-95.

64. Krowka MJ, Fallon MB, Mulligan DC et al. Model for end-stage liver disease (MELD) exception for portopulmonary hypertension. Liver Transpl. 2006:12:S114-6.

65. Goldberg DS, Batra S, Sahay S et al. MELD exceptions for portopulmonary hypertension: current policy and future implementation Am J Transplant. 2014;14:2018-27.

66. Dubrock H, Goldberg DD, Sussman N et al. Predictors of waitlist mortality in portopulmonary hypertension: an analysis of the United Networks for Organ Sharing (UNOS) database. Am J Transpl. 2017 (in press).

67. DeMartino E, Cartin-Ceba R, Findlay J et al. Frequency and outcome of patients with increased pulmonary pressure at the time of liver transplant. Transplantation. 2017;101:101-6.

68. Bandara M, Gordon FD, Sarwar A et al. Successful outcomes following living donor liver transplantation for portopulmonary hypertension. Liver Transpl. 2010;16:983-9.

69. Krowka, MJ, Wiesner RH, Heimbach JL. Pulmonary contraindications, indications, and MELD exceptions for liver transplantation: a contemporary view and look forward. J Hepatology. 2013;59:367-74. 